\title{
キャビテーション・ピーニングによるステンレス錭の 耐キャビテーション壊食性の向上 Improvement of Cavitation Erosion Resistance of Stainless Steel by Cavitation Peening
}

\author{
正 祖山 均（東北大） $\bigcirc$ 山崎 悠樹（東北大[院]）
}

\author{
Hitoshi SOYAMA, Tohoku University, Aoba 6-6-01, Aramaki, Aoba-ku, Sendai, 980-8579 \\ Yuki YAMAZAKI, Tohoku University
}

Key Words: Cavitation, Erosion, Residual Stress, Peening

\section{1. 緒言}

キャビテーションは，流速の増大に伴って液体の圧力が 低下した時に気泡が発生する現象であり，その気泡が崩壊す る時に高衝撃圧を発生する。流体機器の小型・高速化に伴い, キャビテーションが発生して, 性能低下や振動・騒音, 壊食 を生じる(1)(2). なかでも壊食は，流体機器に致命的損傷をも たらすので，キャビテーション壊食における耐壊食性の向上 が望まれている. 現在, 大強度陽子加速器計画 J-PARCに 建設中の中性子源では，水銀に陽子を打ち込み，核破砕によ って生じる中性子を利用するので，水銀に陽子を打ち込むご とに水銀の容器内に圧力波が生じてキャビテーション気泡が 発生して壊食が生じることが明らかになっている(3)(4). この 壊食が容器寿命の重要な支配因子の一つであるので, 耐壊食 性の向上が緊要とされている。これまでに, ショット・ピー ニングを施した面の耐壊食性が向上することが報告されてい る(5). 一方では, キャビテーション気泡の崩壊衝撃力を, シ ヨット・ピーニングのごとく金属表面の表面改質に有効利用 するキャビテーション・ピーニング(CP)が提案されている (6)-(10). キャビテーション壊食と材料特性の相関が十分にわ かっていない現状では，耐壊食性は実際にキャビテーション を材料表面で発生・崩壊させて材料の質量損失量 $\Delta m$ を測定 して求める必要がある.

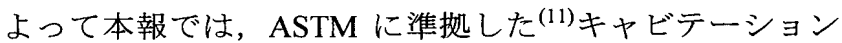
噴流式材料試験装置を用いて，CP を試験片に施し，さらに 壊食試験を行い，キャビテーション壊食における CPによる 耐壊食性の向上を検証した。 また耐壊食性に及ぼす残留态力 $\sigma_{r}$ ，硬さ $H v$ ，表面粗さ $R_{a}$ の影響を明らかにした。

\section{2. 実験方法}

実験に用いた材料には，上記の中性子源容器の候補材料 であるオーステナイト系ステンレス鋼 SUS316L を用いた。 試験片表面は，研削仕上げ，エメリ紙(\#1500)仕上げとした. $\sigma_{r}, H v ， R_{a}$ について, $\mathrm{X}$ 線回折，マイクロビッカース硬さ試 験, 触針式粗さ測定により求めた. 硬さ試験では, 試験荷重 を $490.3 \mathrm{mN}$ とした. $\mathrm{CP}$ の条件は, 上流側圧力 $p_{I}=30 \mathrm{MPa}$, 下流側圧力 $p_{2}=0.42 \mathrm{MPa}$, キャビテーション数 $\sigma=0.014$, ス タンドオフ距離 $s=19 \mathrm{~mm}$ の条件で行った. CP 処理用の試験 片表面はエメリ紙仕上げとし，CP の処理時間 $t_{p}$ は，20 s か ら $80 \mathrm{~s}$ まで $20 \mathrm{~s}$ 毎に 4 種類とした. CP で処理した試験片な らびに CP で処理していない研削仕上げの試験片, エメリ紙 仕上げのみの試験片の計 6 種類の試験片について, 水中キャ ビテーション噴流を用いて壊食試験を行い, $\Delta m$ を測定した. 壊食試験の条件は, $p_{1}=12 \mathrm{MPa}, p_{2}=0.168 \mathrm{MPa}, \sigma=0.014$, $s=19 \mathrm{~mm}$ で行った.

\section{3. 实験結果}

Fig. 1 には, 壊食試験における壊食時間 $t_{e}$ と $\Delta m$ の関係を示 す. キャビテーション壊食の発達過程は $t_{e}$ とともに変化し, $t_{e}=360 \mathrm{~min}$ までに壊食量の時間変化率が一定となった。 $t_{e}=$ $360 \mathrm{~min}$ で $\Delta m$ は，研削仕上げの試験片が最も多く $\Delta m=13.5$ $\mathrm{mg}$ で, 次いで $t_{p}=80 \mathrm{~s}$ における試験片は $\Delta m=12.5 \mathrm{mg}$ であり, $t_{p}=0,20 \mathrm{~s}, 40 \mathrm{~s}$ の $\Delta m$ はほぼ等しく, 最も $\Delta m$ が少なかったの は, $t_{p}=60 \mathrm{~s}$ の試験片で, $\Delta m=10.1 \mathrm{mg}$ であった. $t_{p}$ にって は, $\Delta m$ が CP をしていない試験片と比較して多くなる場合 と少なくなる場合が存在することがわかった. CP をしても いずれ壊食量の時間変化率が一定となる理由は, CP した領 域がキャビテーションにより壊食され, 壊食が未処理の領域 にまで達しているためと考えられる。

Fig. 2 には， $t_{p}$ と潜伏期 $t_{i}$ の関係を示す.ここで定義した $t_{i}$ は, Fig. 1 で壊食量の時間変化率が一定となるときの直線を 外挿して $\Delta m=0$ との交点を $t_{i}$ とした． $t_{i}$ が大なるほど而壊食 性が良いことを示す. Fig. 2 では， $t_{p} \leqq 60 \mathrm{~s}$ までは $t_{i}$ も増大 し, 最も $t_{i}$ が大きいのは $t_{p}=60 \mathrm{~s}$ の場合で $t_{i}=121 \mathrm{~min}$ であっ た. $t_{p}=80 \mathrm{~s}$ まで処理すると $t_{i}$ は低下してしまうことがわか った. また, 研削仕上げの試験片の $t_{i}$ が最も小さく $t_{i}=73$ minであった.

Fig. 3 には， $t_{p}$ と $\sigma_{r}$ の関係を示す. 研削仕上げの試験片に は $\sigma_{r}=286 \mathrm{MPa}$ の引張り残留応力があり, $t_{p}=0$ のエメリ紙仕 上げの試験片は, $\sigma_{\mathrm{r}}=50 \mathrm{MPa}$ の圧縮残留応力が存在していた. このエメリ紙仕上げの試験片は， $t_{p}=60 \mathrm{~s}$ において $\sigma_{r}=-710$ $\mathrm{MPa}$ になっていることがわかった. また, $t_{p}=40 \mathrm{~s}$ において も $\sigma_{r}=-720 \mathrm{MPa}$ と高い圧縮残留応力が導入されていた. 唯 一, 引張り残留応力が存在している研削仕上げの試験片は最 も $t_{i}$ が小さいことから, 引張り残留応力が存在すると耐壊性

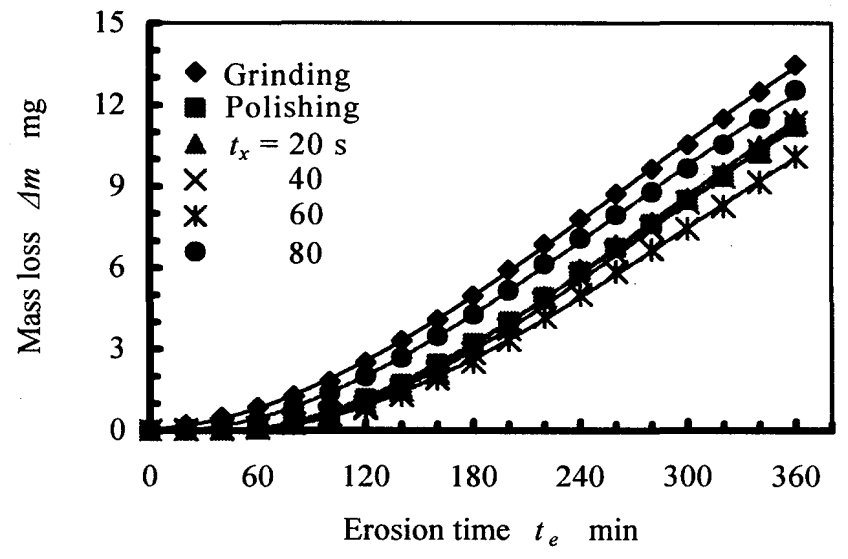

Fig. 1 Mass loss versus erosion time 


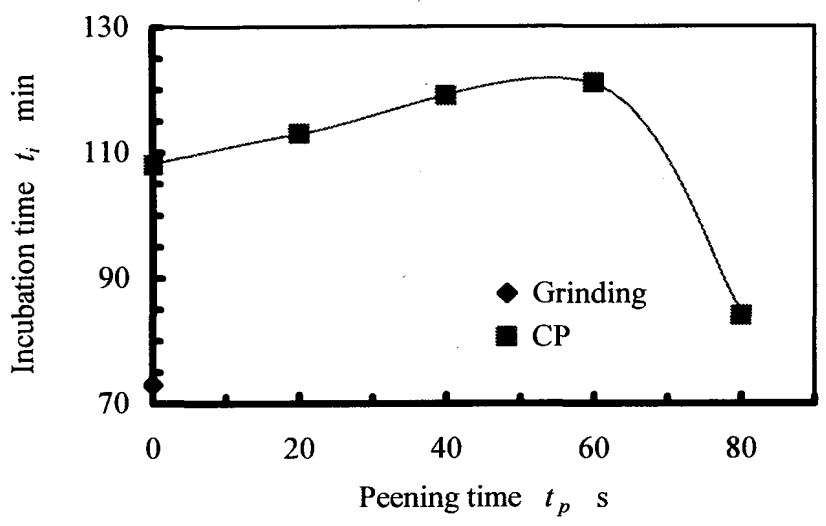

Fig. 2 Incubation time versus peening time

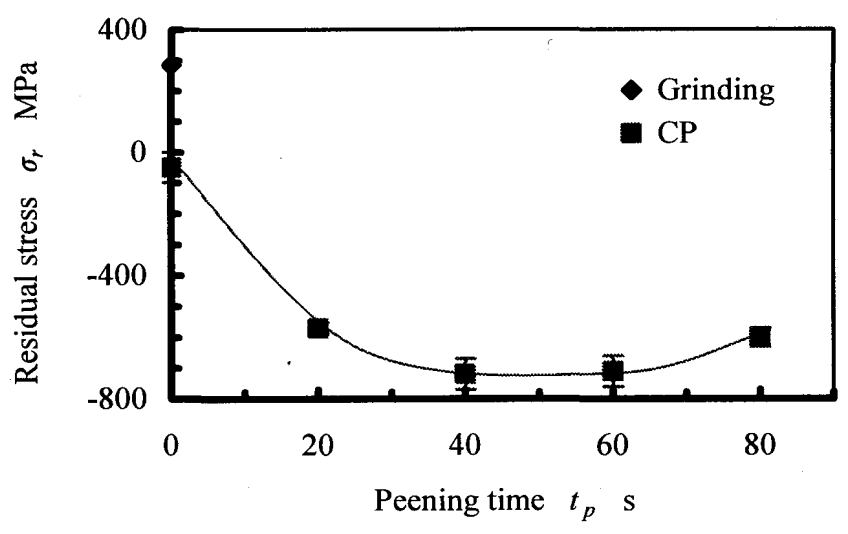

Fig. 3 Residual stress versus peening time

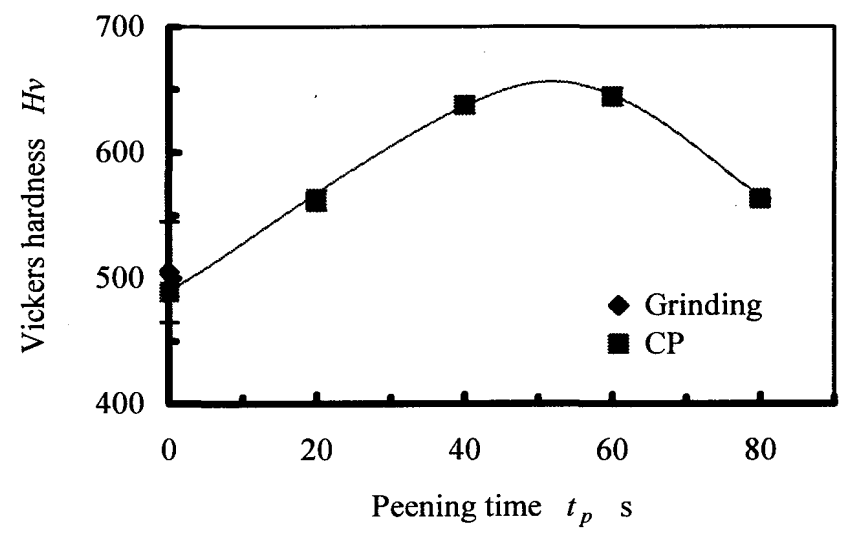

Fig. 4 Vickers hardness versus peening time

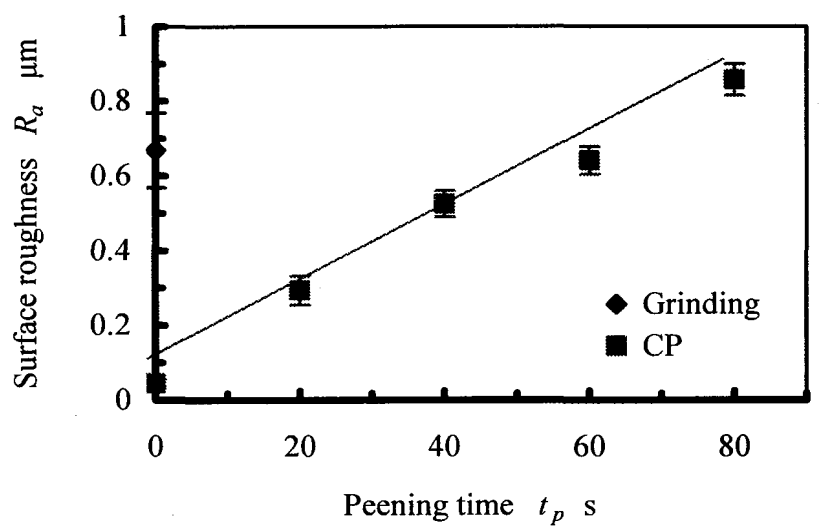

Fig. 5 Surface roughness versus peening time
が低下すると考えられる。一方， $t_{p}=40 \mathrm{~s}, 60 \mathrm{~s}$ で $\sigma_{r}$ が圧縮側 で最大に近い值を示し， $t_{p}=80 \mathrm{~s}$ となると， $\sigma_{r}$ は減少した. これにより， $\sigma_{r}$ が圧縮となることにより $t_{i}$ が増大したと考え られる. しかし， $t_{p}=80 \mathrm{~s}$ で $t_{i}$ が小さいのは $\sigma_{r}$ 以外のパラメ 一タが原因で $t_{i}$ が小さくなったと考えられる.

Fig. 4 には， $t_{p}$ とビッカース硬さ $H v$ の関係を示す. 研削仕 上げの試験片において $H v=496$ であり, エメリ紙仕上げの 試験片では, $t_{p}=0$ において $H v=489$ であり， $t_{p} \leqq 60 \mathrm{~s}$ まで は $H v$ は増加し， $H v$ が最大となる $t_{p}=60 \mathrm{~s}$ では, $H v=644$ で あった. 一方, $t_{p}=80 \mathrm{~s}$ では $H v=563$ と減少した. $H v$ が大き くなると $t_{i}$ も増大する傾向にあるとが考えられる。これは， 一般に硬い材料ほど耐壊食性が大である傾向と一致する ${ }^{(1)}$.

Fig. 5 には, $t_{p}$ と表面粗さ $R_{a}$ について示す. 研削仕上げの 試験片において $R_{a}=0.668 \mu \mathrm{m}$ であり，エメリ紙仕上げの試 験片では $t_{p}=0$ において $R_{a}=0.045 \mu \mathrm{m}$ であり, $t_{p}=80 \mathrm{~s}$ まで $R_{a}$ がほぼ線形に増加した. $R_{a}$ が最大となる $t_{p}=80 \mathrm{~s}$ では， $R_{a}$ $=0.857 \mu \mathrm{m}$ であり, $R_{a}$ が $t_{i}$ を低下させる要因となっていると 考えられる.

\section{4. 結}

オーステナイト系ステンレス鋼のキャビテーション壊食 における耐キャビテーション壊食性の向上を目指して, 研削 仕上げの試験片と, エメリ紙仕上げの試験片に CP を施した 試験片について壊食試験を行い， $\Delta m$ を測定した．CP を施す と $t_{i}$ は増大し, $t_{p}=60 \mathrm{~s}$ で $t_{i}$ は最大となった. しかし， $t_{p}=80$ $\mathrm{s}$ になると， $t_{i}$ は $\mathrm{CP}$ をしていない試験片と比べても小となる ことがわかった． $t_{i}$ が最も小さい研削仕上げの試験片に対し て，最も大となる $t_{p}=60 \mathrm{~s}$ の $t_{i}$ は約 1.7 倍になることがわか った.

初期状態においては， $\sigma_{r}$ が圧縮で大きい場合と， $H v$ が大 なる場合には $t_{i}$ は大となり耐壊食性が良くなる，一方， $R_{a}$ が 大きくなり試験片表面が粗くなると $t_{i}$ は短くなる傾向にある. 耐壊食性には，これらのパラメータが深く関わっていること がわかった。

\section{考考文献}

（1）加藤洋治 : 新版キャビテーションー最近の基礎と発展 一, (1999), 橹書店.

（2）祖山均, 伊藤幸雄, 市岡丈彦, 浦西和夫, 加藤洋治, 大場利三郎，ターボ機械，18，(1990) 691.

(3) M. Futakawa, H. Kogawa, R. Hino, H. Date and H. Takahashi : Inter. J. Impact Eng. , 28, 2 (2003) 123.

(4) B. Riemer et al. : Int. Workshop, Spal. Mats. Tech. 5, Charleston, South Carolina (2002).

(5) W. J. Tomlinson, R. T. Moule and G. N. Blount, Wear, 118 (1987) 233

（6）祖山均 - 山内由章 - 井小萩利明 - 大場利三郎 - 佐藤一 教 - 進藤丈典 - 大島亮一郎，噴流工学，13，1 (1996)25.

(7) H. Soyama, T. Kusaka and M. Saka, J. Mater. Sci. Lett., 20, 13 (2001) 1263.

（8）祖山均・佐々木 圭, 斎藤建一 - 坂 真澄, 自動車技 術会論文集，34，1 (2003) 101.

(9) H. Soyama, K. Sasaki, D. Odiambo and M. Saka, JSME Inter.J., 46 A, (2003) 398.

(10) H. Soyama, K. Saito and M. Saka, ASME J. Eng. Mater. Technol., 124, 2 (2002) 135.

(11) ASTM Designation G134-95, 03. 02 (1997) 537. 